\title{
A performance da memória
}

\author{
Beth Lopes
}

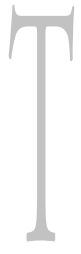

enho dedicado muito do meu tempo ao estudo da memória em minhas pesquisas teatrais, não meramente como um foco escolhido entre tantos assuntos, mas como uma decorrência da prática com performers ${ }^{1} \mathrm{em}$ minhas direções ${ }^{2}$ e em minhas aulas de atuação na universidade. ${ }^{3}$ Estudando e exercitando os procedimentos dos grandes mestres do teatro pude perceber a importância da mnemotecnia e as várias formas experimentadas por eles. A memória, evidentemente, é a raiz dos procedimentos criativos do performer. Quando se pensa em uma cartografia e nos meios pelos quais o performer a experimenta em processos artísticos e espetáculos, são muitos os exemplos do uso da memória como um impulso, como uma motivação, como um tema ou como um procedimento para tornar o trabalho com o seu corpo um objeto cultural. Desde o grande mestre da "memória das emoçôes", Constantin Stanislavski, a recorrência ao tema tem provocado bastantes controvérsias, se uma técnica de atuação, um estilo ou simplesmente a substância com a qual o performer transforma a sua imaginação e as suas emoçōes em arte. De qualquer modo a questão está sempre associada ao mesmo desejo: a produção de uma arte viva, uma arte da presença e do presente (mesmo quando a tônica é o passado).

Beth Lopes é encenadora e professora do Departamento de Artes Cênicas e do Programa de Pós-Graduação em Artes Cências da ECA-USP.

1 Uso o termo performer em vez de ator me referindo aquele que não se restringe à interpretação teatral no sentido convencional, mas transita por diferentes campos do conhecimento, desfronteriza as linguagens, amplia as nocoes espacio-temporais e fricciona as relações entre o real e o ficcional incorporando estados emocionais, subjetividades, memórias, criando a sua poética particular.

2 Os processos de performances e espetáculos que dirigi com a formação mais recente da Companhia de Teatro em Quadrinhos foram compostos com a memória. Encontrei neste grupo de performers a parceria perfeita para estas investigaçōes. Aura Cunha, Eduardo Mossri, Leonardo Moreira e Maria Helena Chira têm sido performers no verdadeiro sentido, criadores e construtores de um percurso artístico sólido e persistente.

3 Em 2006 fiz uma pesquisa de pós-doutorado com o apoio do CNPq na UFSM, em Santa Maria, RS, onde pude analisar aspectos da memória do performer na perspectiva dos estudos sobre Análise do Discurso, com a professora doutora Amanda Eloína Scherer, no Programa de Linguística do Curso de Letras. 
A relação que quero abordar dentro deste grande contexto é o da memória como um procedimento performativo que produz um discurso que tem um papel histórico e pedagógico.

A amplitude do tema da memória vai da neurociência à poesia e oferece uma variedade de reflexões que perpassam diferentes campos do saber. Meu objetivo é abordar o tema nas imediaçôes dos conceitos de sujeito, linguagem e história com a intenção de partilhar alguns significados e experiências.

Se pudesse demarcar com exatidão quando e o que me atraiu para este assunto situaria mais ou menos no final dos anos 80 quando tive contato com as experiências de Eugenio Barba e seus atores em demonstrações de trabalho, workshops e textos. A minha percepção sobre o papel da memória na corporalidade do performer foi se sedimentando com a prática, sentida na própria pele, no treinamento com as partituras de açōes de corpo e voz que realizei com Richard Fowler, Iben Raussmussen Nagel e Jan Fersley, bem como, espetáculos, palestras e demonstraçôes de trabalhos dos atores e do diretor do Odin Theatret. Praticando compreendi a diferença entre buscar um corpo fictício do de uma pessoa fictícia ${ }^{4}$ o que significou uma abertura para a compreensão da atuação performática. Estas experiências com outras também marcantes na minha prática como atriz e diretora me levaram a estas reflexóes que misturamse também às memórias da minha vida. Enquanto vivia a dolorosa experiência da luta entre a vida e a morte de meu pai ${ }^{5}$, ao mesmo tempo em que começava um novo processo artísticopedagógico no curso de Artes Cênicas da Universidade de São Paulo, uma idéia de Barba em alguma leitura que colhi em seus textos falava que o maior desafio para um ator seria representar um velho. Com esta idéia realizei os meus dois primeiros trabalhos com a memória da memória, como um procedimento de atuação (memória dos performers) e também como tema do processo criativo: "Doce lembrança" (a partir de 'Memória de Velhos', de Ecléa Bosi) e "Tempo de Viver" (baseado no livro homônimo de Oliver Sacks).

Este momento inaugural foi significativo porque pude contar com alunos sérios ${ }^{6}$ e interessados na investigação que se desdobrava a partir do eixo central e com quem fui tecendo as fibras dos diferentes conhecimentos que ali se articulavam. As camadas de informações que se acumulavam na prática física deixavam entrever o mundo de cada um dos participantes, sua história e ideologia fundidas com as lembranças dos outros surgidas em suas recordações, além das figuras dos velhos trazidas pelas fontes de Ecléa Bosi e de Oliver Sachs. A medida que eu via as lembranças se desenharem nos corpos dos performers eu sentia um prazer de olhar e ver os diferentes discursos que esculpiam aqueles corpos, transformando aqueles jovens em velhos por inteiro. Era algo que vinha de um lugar profundo e desconhecido, mas que trazia a intensidade da vida e da morte. Vi que

\footnotetext{
Barba, 1994, p. 57.
}

5 Aos 80 anos, meu pai sobreviveu a uma isquemia cerebral, mas passou quinze dias em coma e posso dizer que foi o meu primeiro confronto com a concretude do fim da existência. Quando ele foi se recuperando foi relembrando, com clareza, os momentos infernais e solitários por que havia passado. Estes relatos me alertaram para a profundidade da memória e para as marcas que produziam no corpo dele, no meu e de todos aqueles que estavam ao seu redor. Depois disto fiquei mais interessada nos mecanismos neurológicos (também porque meu irmão é neurocirurgião) da memória, obviamente porque também queria protelar a dor da perda dos familiares e saber mais ajudou muito nos anos que se seguiram, na vida pessoal e profissional.

6 Ana Galotti, Eduardo de Paula, Guadalupe Vivanco, Mara Leal, Vera Canolli. 
se tratava de um lugar de alteridades e o quê os performers amalgamavam na materialidade dos corpos se constituía em modos de conhecimento de si e de sua história. Por esta razão uma noção de sujeito para este estudo foi evocada, a do sujeito que aparece representado, transformado por um discurso dominante. Este sujeito $^{7}$ que não é tomado como um ser único, em sua condição individual, visto que é formado pelo discurso do outro e se encontra em posição de assujeitamento, se encontra representado pelos processos históricos e sociais. O performer, nesta abordagem, torna-se um sujeito de si mesmo, considerando que o discurso constituído pelo léxico de palavras e gestos é pontuado por referências trazidas no cruzamento dos outros discursos. São vários discursos em um só. Cada ação, olhar, andar ou sentir está associado a alguém que de alguma forma se insere na sua história, na da sua coletividade, na do seu tempo e lugar. O discurso do performer constitui sua linguagem a partir do contexto simbólico da sua memória, ligando materialmente, inconsciente e ideologia. O tempo, passado, presente e futuros são totalmente intercambiáveis. Na multiplicação dos tempos e espaços dos fragmentos da memória, se criam dobras que se dobram sobre si mesma numa sequência de remissões ao conjunto que as lembranças pertencem. Criar uma narrativa com a linguagem corporal significa agregar uma quantidade de fatos sobrepostos da memória que correm em diferentes direçôes. Sendo assim , os discursos da memória são sempre portais de inscrição de outros saberes, tempos e modos de existência.
O corpo é o espaço da memória do performer, o lugar onde os sentidos se constituem perante o publico. As ações compõem a sua linguagem, história e ideologia (todos têm uma). O espaço da memória é um lugar de trânsito de idéias e sentimentos, um lugar de subjetividades, de revelação da interioridade do performer na razão direta da sua exterioridade. As emoções que o performer perpassa na sua pele, na sua carne, na sua expressão inscreve uma 'matriz de si'. ${ }^{8}$ Ao acessar as vias profundas da vida pessoal do performer, a imaginação evoca, distorce e muitas vezes reinventa as lembranças, fazendo-as vibrar nos gestos compostos por diferentes niveis do 'real'?. Lembrar não significa fidelidade aos fatos como eles realmente aconteceram. Lembrar está ligado ao imaginar, ampliar, omitir. Distorcer faz parte dos mecanismos da memória, na medida em que nossa imaginação acrescenta ou retira os fatos como uma auto defesa da sua mente. Tudo depende da natureza das conexões que o córtex estabelece no armazenamento ou dos fatores externos ou internos que afetam a evocação da memória.

Da mesma forma que a memória oferece uma variedade de reflexões que atravessam os conceitos de sujeito, ideologia, história, como ferramenta teatral possibilita uma experiência de linguagem capaz de colocar o tempo passado como um meio de compreensão do presente. $\mathrm{O}$ discurso corporal gerado pela percepção e expressão usa mecanismos que cada um perfaz a seu modo. No trabalho com o seus arquivos, conscientes ou inconscientes, o performer vai buscar formas de materializar aquilo que sente

7 Trago a noção de fragmentação do sujeito articulado por Michel Pechêux, na Análise do Discurso.

8 Courtine e Haroche (1988) entendem por 'matriz de si' como a individualização pela expressão que se inscreve na história da interiorização progressiva, pelo sujeito, pelas tensões que resultam em um conjunto de relaçóes e de dependências sociais mais fechadas e complexas.

9 Relaciono o 'real' ao conceito de representação mimética visto não só como imitação da vida, mas como a noção de uma constelação de referências imaginativas que se incluem entre as diferentes realidades e mundos virtuais. 
daquilo que relembra. $\mathrm{O}$ discurso que se constitui é heterogêneo, fragmentado e disperso por envolver os diferentes sentidos pelos quais ele é afetado.

$\mathrm{Na}$ viagem pelas redes neurais, zonas sensoriais e motoras do cérebro o performer reconstitui as imagens internas da sua vida enquanto o corpo vai revelando as marcas dos seus afetos. O trabalho do performer consiste em se confrontar, dia a dia, com a percepção de si. Amplia-se, desta forma, o poder de observação de si e dos outros. A sua expressão se constitui não só em um traço sensível do seu processo fisiológico e psicológico mais íntimo, mas também é a expressão individual resultante de um conjunto de relaçóes sociais sobre a qual pesam as tensões e os dilemas de sua época. A corporeidade do ator, o conjunto de marcas que particularizam a sua fisionomia e a sua expressão, é o que media as relações entre as açóes e as emoções privadas, mas também é um lugar da expressão pública na medida em que exterioriza as conexões e desconexões trazidas dos diferentes territórios da existência. "O corpo humano é inteiramente habitado por analogias: Por meio dela ele toma seu sentido, libera-se de sua opacidade, confia seus segredos." $10 \mathrm{O}$ corpo é a morada que abriga as memórias, o lugar de sonhos e desejos, mas também das ambigüidades, dos ressentimentos, dos medos, do esquecimento.

Como no conhecido episódio das 'Madalenas' de Marcel Proust, em Caminho de Swam, o momento do chá com o bolinho provoca um estranho e imenso prazer, instante que ele compara a sensação de desprendimento das suas preciosas lembranças de Combray ao prazer do amor. Assim como a memória involuntária usada por Proust e por tantos outros na literatura ou na filosofia (Walter Benjamim, Henri Berg- son) o que ocorre com o performer é semelhante. O performer é invadido por uma sensação, operada pela sensibilidade, de pertencimento e de apreensão das relações entre o presente e o mundo familiar das lembranças. $\mathrm{O}$ corpo do performer na medida em que vai sendo perfurado por esta força criativa torna-se signo composto por toda a sorte de elementos que trazem não a representação, mas a presença vida do outro: hábitos, costumes, atitudes e comportamentos que emergem das experiências vividas, sonhadas, imaginadas ou desejadas. Na composição da performance os fragmentos da memória engendram sentidos e se organizam para tornar o indizível aquilo que se quer dizer. $\mathrm{O}$ caráter autobiográfico que as reminiscências inscreve na corporeidade do performer descreve épocas, lugares, familiares, amigos, pessoas que circundam a vida de cada um. Além dos espaços, lugares e pessoas as recordações são acompanhadas por amuletos/objetos que dão cor, textura, volume, cheiro e sabor a imagem da cena, dando materialidade e intensidade para o presente. Caixas, espelhos, sapatos, vestidos, comidas, livros, brinquedos, música, fotografia são objetos recorrentes que o tempo, o espaço, as estações, a infância, a juventude, a velhice, a morte, acolhem no seu cenário. Ações como guardar, arrumar, separar, organizar, sentar, esperar, dormir, sonhar, acordar, dançar e cantar mesclam estados de repouso e de tensão em seu repertório. A sexualidade, a sedução, a perda, a despedida, a dor, o amor, o riso, são estados sensíveis que desvelam a memória do seu corpo.

Não são importantes as lembranças em si, mas o impulso acionado para lembrá-las, o discurso que se constrói com estas vibrações e o que se oferece à uma outra experiência vibrátil - a do espectador. ${ }^{11}$ Trata-se antes de tudo de

10 Courtine e Haroche, 1988, p. 53.

11 Tomo emprestada a expressão “corpo vibrátil” usada por Suely Rolnik em vários textos e que faz parte das reflexões sobre a esquizoanálise, uma dimensão crítica da clínica psicanalítica recorrente de pensamentos de Deleuze e Guattari. 
capturar um instante único do campo destes sentidos ${ }^{12}$. O disparador das memórias que oxigena e desobstrui a passagem das imagens para o corpo. Assim o quanto e o que cada ator expõe do seu mundo particular é um trabalho sobre si mesmo, sobre as suas matrizes. O prazer ou o infortúnio que as recordações pessoais provocam despertam emoções que vão impregnar de batimentos rítmicos os corpos singularizando a sua expressão.

O que menos importa é recordar emoções para construir personagens, mas sim, como a lembranças fazem o corpo do performer 'vibrar' quando atingido pelas emoções, impressões e sensaçôes. Walter Benjamin diz que nos gestos da memória involuntária o passado aparece como um relâmpago. As sensações que reverberam na corporalidade do performer torna o seu trabalho um sinalizador da subjetividade de seu tempo, criando uma ponte entre a memória pessoal e a ficcional. Desta forma tento mostrar como a memória pode ser uma ferramenta não apenas importante para a formação, para o treinamento e para o processo criativo do performer, mas instauradora de uma linguagem singular, um modo de perceber e compreender o mundo contemporâneo.

$\mathrm{Na}$ relação direta com a trajetória contínua da atuação/ não atuação proposta por Michael kirby,o trabalho com a memória não busca representar alguém, situação, lugar e tempo, mas busca o corpo esvaziado das matrizes simbólicas que o remete aos modelos formais de representação. Neste lugar as realidades ficcionais se estreitam com as realidades da vida. O corpo torna-se um portador de informações, de mensagens, de fluxos sensoriais, de sensaçōes vivas.
Neste sentido o papel que o movimento da performance, desde os anos 60, traz para o corpo do performer contemporâneo é fundamental. Tento fazer algumas conexões entre a memória e a performatividade ${ }^{13}$. Uma primeira acepção do termo performance se refere aos diversos movimentos artísticos dos anos 60 e 70 que foram denominados de happening, collage, environmental art, assemblage, action painting, body art. Ainda vigorava o intento vanguardista de superar as linguagens artísticas da tradição. Aqui se reivindica a idéia de que a performance deve excluir de seu campo a noção de representação, colocando a ênfase na ação. O performer não representa o papel de outro, mas se apresenta como ele mesmo, assim como o cenário não deve recriar outro mundo, já que o espetáculo se recusa a ser (somente) dramático. Aqui o que se joga na cena é o próprio eu do performer como no caso da automutilação de Rudolf Schwartzkogler, artista vinculado a body art, que morreu em decorrência de ter cortado o próprio pênis. É um caso extremo em que a arte, em vez de reencantar a vida, termina-a, num ato radical e performático, que inaugurou a arte abjeta. A performance possuía um ineditismo e um sentido de ruptura com a arte do passado assim como as vanguardas históricas - cubismo, o surrealismo, o dadaísmo, expressionismo, o futurismo. Não faltaram atitudes performáticas tais como as de Michel Duchamp (arte conceitual) e mais tarde a de Jackson Pollock (action painting), e experiências radicais de artistas como Allan kaprow (happenings) e do Black Mountain College, onde o músico John Cage (música aleatória) e o coreógrafo Merce Cunninghan (event), brilharam dentro desta busca do choc.

12 Foi marcante para mim, em um workshop sobre a improvisação estruturada e espontânea com François khan quando ele observou que na repetição de uma ação que eu estava trabalhando, não tinha mais o mesmo o impulso da primeira vez. Eu percebi que estava equivocada em repetir a mecânica das açôes, o que eu tinha que manter era a energia do momento em que a recordação tomou corpo. François trabalhou com Grotovski e realiza uma pesquisa sobre a improvisação com a memória.

13 A ação do performer. 
Por outro lado, a performance adquire um sentido mais abrangente na contemporaneidade. Depois dos anos 70, tendo superado a questão da ruptura com o passado, o artista constrói uma arte combinatória ${ }^{14}$, operada através de apropriaçóes de procedimentos artísticos anteriores. A apropriação de um signo do passado recente, fecundando a arte atual, possibilita a permanência desse passado em novas condições: é uma forma de preservá-lo transformando-o. Assim, a performance dos anos 60/70 fo integrada à estética e à prática do teatro contemporâneo: o performer apresenta uma ação corporal (gesto, voz, movimento) com ou sem representação, com ou sem jogo de ilusão, estruturada pela imagem ou pelo texto, utilizando tecnologias inovadoras ou tradicionais. $\mathrm{O}$ dispositivo performático permite ao teatro questionar a representação e ao performer questionar sua identidade. A dimensão performática abre um campo de forças por onde se espalham polaridades em tensão, que coexistem sem que existam linhas claras de demarcação. 'Performar' coloca em jogo as noções de naturalismo (mostra ele mesmo como é) e a teatralidade (em extrema situação de ação) ${ }^{15}$ do acontecimento e não da representação. A tensão entre vida e arte, entre performer e personagem, entre técnica e $o$ acaso, entre o performer e o espectador, entre a contingência e a coerência. Nesse campo de forças, atravessado por mil discursos, tatuado por mil culturas, desarticulado por mil vanguardas surge o corpo vibrátil do performer. Assim como o performer nega o sujeito identitário e pleno e aposta nos processos de dessubjetivação e desidentificação, o teatro performático vai buscar na desarticulação dos rituais e da representação. A memória do performer surge então como potência de imaginação e o que nos interessa em suas reminiscências é a performance da ação e da fala, isto é, principalmente seus ritmos e tropeços, lapsos e vazios.

A dinâmica criadora que a memória produz na fricção entre o corpo no teatro e corpo cotidiano, enlaçando a problemática da ação e presença na performance, tem um papel histórico e pedagógico. Constantin Stanislavski, inspirado pela psicologia experimental de Théodule Ribot ${ }^{16}$ torna a memória das emoções um dos eixos do seu sistema de atuação, onde a representação motora das experiências emocionais vividas gera o método das ações físicas influenciando inúmeros artistas das geraçōes dos séculos 20 e 21 . Rudolf Laban, no início do século 20, também impulsionado pelas experimentações de Ribot volta-se para a questão da vibração e suas ressonâncias esotéricas que induzem coordenaçôes cinestésicas. Centrado nos ritmos e gestos perdidos pela perda de percepção que condicionam o comportamento da vida moderna, Laban elabora a improvisação cinestésica com as variáveis do peso do corpo no tempo e no espaço visando despertar a 'memória involuntária'.

A partir dos anos 60 , período marcado também pelas revoluções políticas e movimentos artísticos radicais, o teatro de Jersey Grotovski, Peter Brook e Eugenio Barba renovam a idéia da memória e o corpo em suas experimentações são portadoras de uma poesia singular. $\mathrm{O}$ corpo adquire um valor essencial, como um refúgio da memória, uma espécie de memória das origens, elevando-se de uma linha da tradição em direção a uma multiplicidade cultural.

Grotovski nas diferentes fases da sua trajetória artística levou sua pesquisa com o ator

14 Pensamento amplamente discutido com Luíza Jatobá, psicanalista e dramaturgista.

15 Schechner, 1994, p. 126

16 Para Ribot o que subsiste dos estados de consciência, emocionais e das percepçôes fica registrado pela cinestesia graças a organização das nossas capacidades motoras. 
ao lugar profundo e arcaico da memória do ser O exemplo mais conhecido de Grotovski com a memória conta que no processo de Principe Constant, Riszard Cieslak não trabalhou com a personagem de Calderón, mas com o seu acervo de memórias pessoais e uma das mais marcantes foi uma composição com a sua primeira experiência amorosa, o que gerou uma inesquecível partitura do espetáculo. No final da vida Grotovski trabalhava com os antigos cantos vibratórios, cantos que serviram no passado aos propósitos de rituais e que, para ele, produzem um impacto sobre a cabeça, o coração e o corpo dos atuantes. Tais cançôes primitivas deveriam trazer à cena o fluxo das pulsões interiores no conjunto de uma estrutura performativa muito precisa. Na teoria e na prática, a Antropologia Teatral, segundo Barba propõe o estudo do comportamento humano, da presença física e mental em situação de performance organizada de modo diferente do cotidiano. A partitura física para Barba é guiada pela nossa memória, e é ela que permite penetrar embaixo da pele das diferentes épocas e encontrar os múltiplos caminhos que nos levam às origens. Peter Brook, que há muitos anos reúne atores de diferentes horizontes culturais busca criar novas relaçóes com os elementos que aprisionam a língua, os gestos, os lugares e espaços sociais na história da origem de cada um.

O teatro-dança de Pina Bauch também é totalmente feito de memórias. Tirado da história e da memória dos seus performers também vindos de diferentes países, a diretora, dançarina e coreógrafa 'escreve' seus espetáculos com os corpos em movimentos repetidos, fragmentados, expandidos, miniaturizados, buscando a compulsão dos corpos. Com um sistema de perguntas e respostas que devem conter as experiências e memórias pessoais, a diretora cria seus espetáculos com as reações corporais dos seus performers. Um bom exemplo pode ser visto (vídeo) no processo do Café Muller quando Pina propõe a seguinte pergunta: Mostre algo que você aprendeu recentemente?

Um dos performers responde com a execução de uma partitura de tradução simultânea à música de Gershwin, The man I Love, em linguagem de surdo e mudo. Neste procedimento o performer tem que buscar em suas memórias associações e articular a resposta cênica, simples, sem atuação, sem personagem. Observando o espetáculo, onde esta cena aparece, se percebe que a técnica de montagem de Pina segue um outro impulso, criando novas intersecçōes e relações com as respostas e recriando a sua própria história pessoal. Ela sempre busca questionar o sentido do teatro e a sua maior aproximação com a vida, questóes que se desenvolvem no limiar das teorias sobre a performance. A sua dança-teatro alia representação mimética, emoção e movimento. Com os procedimentos da 'dramaturgia da memória'17 ela busca não uma cena, mas uma sensação física, uma energia, um fluxo.

Com as memórias de sua infância e da guerra Tadeuz Kantor concebeu espetáculos memoráveis. Histórias contadas com lembranças que misturam os objetos aos atores, expressando a idéia que kantor (teatro da morte) descobre que nada melhor expressa a vida que a ausência de vida, e a morte se converte em tema central de seus últimos espetáculos (Classe Morta, Wielopole-Wielopole e Que Vivam os Mortos). E com a vida vem o passar do tempo, os espaços da memória, a imagem da recordação, a vida que se foi. Para ele, no entanto, o teatro não é um espaço de verossimilhanças, mas de similitudes.

17 Este termo foi usado na tese de doutorado de Lícia Maria Moraes Sanchez, com quem pude ampliar meus conhecimentos sobre os procedimentos criativos de Pina Bauch, com quem, Lícia havia realizado um estágio, anos atrás, no Tanztheater Weppertal, em Wuppertal Buhenem, Alemanha. 
A atuação no teatro euroasiático é sutilmente pontuada por interferências de toda a natureza da memória e enfatiza o discurso do corpo antes mesmo de qualquer representação com as palavras. Richard Schechner denomina este movimento como um 'fenômeno intercultural', que faz com que o corpo se comunique em qualquer lugar, em qualquer língua por meio da sua teatralidade.

$\mathrm{O}$ teatro da vanguarda norte-americana coleciona um grande número de experimentos a partir dos anos 60, onde a memória e a performance surgem como uma reação traumática de pós-guerra e continuadora dos movimentos dadaísta e futuristas do início do século. Sem a pretensão de cartografar os grupos experimentais deste período, mas situar, relaciono o que assisti em VHS ou DVD ${ }^{18}$ com o que associei com a idéia da performance da memória. $\mathrm{O}$ Living Theater, The Open theater, Performance Group, Wooster Group, Mabou Mines, The Bread and Puppet, The Playhouse of the Ridiculous, The Ridiculous Theatrical Company, são grupos que têm em comum o desejo de tornar o teatro tão intenso quanto um acontecimento vivo, com todos os riscos e as contradições da vida. Nas inúmeras publicações de Richard Schechner (pouco traduzidas no Brasil) pode-se entender a grandeza deste teatro inovador. Especialmente influenciados pelo músico John Cage, através de quem foram tra- zidas as idéias de Marcel Duchamp e Antonin Artaud, surgem nomes ${ }^{19}$ ligando o teatro, música, ópera, dança e cinema ao da performance art, rompendo as fronteiras entre gênero, estilo, linguagem, mas principalmente entre a vida e a arte, o que inclui uma radical explosão na relação entre o performer, a performance e o público. $\mathrm{O}$ espaço assim, torna-se um lugar sem limites para estes acontecimentos como o que acontecia no Peformance Garage (lugar dos ensaios e apresentações do Performance Group dirigido por Schechner) onde o grupo usava todos os espaços envolvendo o publico na encenação, e para a exploração da imaginação e do tempo (Robert Wilson). O espaço da cena invade as ruas, as praças, como o Bread and Puppet que usava bonecos gigantescos e envolviam um grande numero de participantes. A linguagem da performance ganha espaço no vocabulário e na prática da escritura da cena americana. $\mathrm{O}$ teatro performático ${ }^{20}$ que no sentido Schechneriano tem uma ênfase no 'fazer', combina diferentes açōes e linguagens, mas é sobretudo um lugar de manifestos, testamentos, confissões, documentários, histórias de vida, de abertura das 'matrizes de si' dos artistas e consequentemente, do olhar do espectador. $\mathrm{O}$ corpo neste tipo de espetáculo torna-se carne com o engajamento físico do performer. Os performers falam como eles mesmos para o público e sobre aquilo que acreditam, sem marcas de re-

18 Participei, como Visiting Scholar, para o qual recebi bolsa pós-doutoral da Capes, no departamento de Performance Studies, da NYU, no segundo semestre de 2009, da disciplina USA Experimental Performance: the 60s To The 80s, dada por Schechner. Contamos, durante as aulas, com a presença de Judith Malina (Living Theater), Lee Breuer (Mabou Mines), Everett Quinton (Ridiculous Theatrical Company) e Richard Foreman (Ontological-Hysterical Theater).

19 Allan kaprow, Andy Warhol, Carolee Schneemann, Jack Smith, Yvonne Rainer, Trisha Brown, Lucinda Childs, Ann Halprin, Steve Paxton, Laurie Anderson, Philip Glass, Meredith Monk, Julian Beck, Judith Malina, Josefh Chaikin, Peter Schumann, Charles Ludlam, Lee Breuer, Richard Schechner, Spalding Gray, Elisabeth LeCompte, Robert Wilson, Richard Foreman.

20 Expressão escolhida por Josette Féral (2008, Brasil) para falar desta combinação de linguagens e que, segundo ela, tem a mesma intenção que a expressão pós-dramático de Lehmann e pós-moderno. 
presentação. Os espetáculos levam o processo para a cena, do modo mais profundo que possa ser um processo e o que se improvisa é vivido como um momento único. Os ensaios, mesmo com a produção de partituras de ações físicas, servem para fortalecer as convicçōes dos performer. Um exemplo forte se destaca pelo uso de material autobiográfico: o teatro performático de Spalding Gray e Elisabeth LeCompte. Na trilogia Three Places in long Island, do Wooster Group, que consiste em Sakonnet Point (1975), Rumstick Road (1977), Nayatt School (1978) e mais tarde foi incluído um epílogo desta linhagem, Point Judith (1985), LeCompte performa a própria vida de Spalding. Como procedimento de criação realizam improvisações com a memória usando os personagens $\mathrm{da}$ vida de Spalding. Em Rumstick Road, por exemplo, são colocados em cena diálogos entre Spalding, sua avó, seu psiquiatra, onde conversam sobre o suicídio da mãe dele. Em Point Judith, ele é a mãe e o pai, sempre com o discurso voltado diretamente para o público.

O procedimento da memória, como demonstrado nestes exemplos, segue um caminho do teatro para a performance que se fortalece no teatro contemporâneo. ${ }^{21}$ Lipsynch (2009), a mais recente produção de Robert Lepage, faz da memória da voz e da interferência tecnológica o mote da performance. Durante nove horas, nove histórias e nove protagonistas exploram a comunicação oral usando todos os dispositivos (telefone, rádio, filmes silenciosos, playback, sincronização) e com eles criam identidades e emoções para as distintas vozes (do canto, da consciência, do além, alucinadas). Uma das histórias mais interessantes mostra a obsessão da filha em descobrir o que o pai já morto falava para ela quando criança, em momentos da família gravados em 'superoito', sem áudio. Ela recorre ao auxílio de uma mulher muda para ler os lábios do pai e descobre que o que ele fala não passa de algumas frases banais. Em outras inúmeras e fatigantes tentativas com um ator de dublagem, a protagonista da história tenta 'sincar' uma voz ideal na imagem do pai. No programa, Lepage diz que o espetáculo fala da significação e da interação da voz, discurso e linguagem na moderna expressão humana.

Neste conjunto heterogêneo de experimentadores, os procedimentos, ou seja, a fatura e os códigos artísticos, a linguagem, são reinventados e é a prøpria noção de arte que se expande, englobando uma variedade caleidoscópica de signos da cultura e de manifestações. Tudo isto tem como pano de fundo a experimentação teatral, a desconstrução dramática, a recusa da representação e a performance como formas de resistência.

O que se pode concluir sobre com as questôes que envolvem a memória do performer é que a imersão na interioridade tem um fio invisível conectado para o exterior pela força da linguagem. Enfatizando a ação e o acontecimento ele gera uma forma de expressão que reflete a história e a formação ideológica que o representa. Desta forma, este discurso não requer homogeneidade e unicidade do sujeito, mas faz da linguagem um ponto de partida, de revelação.

Como a história pode ser contada com a linguagem do corpo do performer? Considerando que cada época tem o seu dilema é a partir dele que o corpo se manifesta. O performer, citando Grotovski, é um construtor de pontes. Decifrar o corpo performático permite atravessar estas pontes e recontar a história. A apropriação da linguagem do corpo produz novos valores de uso para as performances que, deste modo, deslocam, deformam e subvertem os códigos da arte. $\mathrm{O}$ performer não antecede a práti-

21 Josette Féral (2008) discute de forma muito interessante o que ela denomina como teatro performático - uma tendência na contemporaneidade de colocar a ênfase na ação. 
ca, sua identidade é desconstruída e recomposta e assim efetivamente transformado pelos materiais que transforma.

Para dar terminar e dar continuar a esta reflexão cito Giorgio Agambem que, propõe uma profanação do sagrado, com o intuito de liberá-lo para o uso comum. Criar um novo uso, desativando o velho, transformá-lo em meios puros. Ele diz também que hoje o homem deve se importar mais com desarticular do que com juntar. Diz que o homem não chegou a bons resultados querendo conjugar diferentes ele- mentos. É claro que sempre as polaridades estarão em tensão, mas que o filósofo quer ressaltar é que o homem sempre se preocupou demais em articular, como por exemplo, na conjunção da linguagem e da vida, mas que o momento exige uma ênfase nos processos de desarticulação, dessubjetivação. Também enfatiza que para o homem contemporâneo a grande armadilha é a busca de identidade e que o mais fecundo é investigar o caráter da mascarada que há em toda a identidade e estrategicamente se jogar em processos de desidentificação.

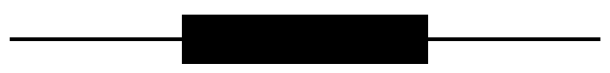

\section{Referências bibliográficas}

AGAMBEN, Giorgio. Profanaçōes. São Paulo, Boitempo, 2007.

BARBA, Eugenio \& SAVARESE, Nicola. A Dictionary of Theatre Antropology: the Secret Art of the Performer. New York, Routledge, 1991.

COHEN, Renato. Performance como Linguagem. São Paulo, Perspectiva, 1989.

COURTINE, Jean Jacques \& HAROCHE, Claudine. Histoire du visage: Exprimer ET taire sés emotions. Paris, 1987.

FÉRAL, Josette. Pour une poétique de La performativité: Le théâtre performatif. São Paulo, 2008.

HARDING, James M. \& ROSENTHAL, Cindy (Eds.). Restaging the sixties. Ann Arbor, University of Michigan Press, 2006.

KIRBY, Michael. Acting and not-acting: In A formalist theater. University of Pennsylvania Press, 1987.

LEHMAN, Hans-Thies. Teatro Pós-dramático. São Paulo, Cosaq Naify, 2007.

. Environmental Theater. New York, Applause, 1994.

. Performance Studies: An Introduction revised and expanded second edition. London/New York: Routledge, 2006.

SCHECHNER, Richard \& WOLFORD, Lisa (Eds.). The Grotowski Sourcebook. New York, Routledge, 1997. 
RESUMO: Este estudo sobre a memória é um tema recorrente na mais recente produção artística e pedagógica de Beth Lopes. Como conseqüência de experimentaçōes em torno do performer, performance e performatividade este tema foi fortalecido pela reflexão teórica destas práticas a partir da abordagem da Análise do Discurso, considerando que as reminiscências pessoais do sujeito que atua no teatro são materializações também, de discursos que refletem um momento histórico e coletivo. O objetivo principal da pesquisa é aumentar e consolidar a compreensão sobre os traços da performatividade que marcam o trabalho do ator contemporâneo.

PALAVRAS-CHAVE: Memória, performer, performance, performatividade, Análise do Discurso. 